\title{
Anxiolytic-like Effect of Essential Oils Extracted from Lippia alba and Lippia citriodora
}

\author{
Paul Alan Arkin Alvarado-García ${ }^{1, *}$, Marilú Roxana Soto-Vásquez ${ }^{2}$, Luis Enrique Rosales-Cerquin ${ }^{1}$, Bertha \\ Mirella Alfaro-Ttito ${ }^{3}$, Elda Maritza Rodrigo-Villanueva²
}

\section{Paul Alan Arkin Alvarado- García ${ }^{1, *}$, Marilú Roxana \\ Soto-Vásquez ${ }^{2}$, Luis Enrique \\ Rosales-Cerquin', Bertha Mirella \\ Alfaro-Ttito ${ }^{3}$, Elda Maritza \\ Rodrigo-Villanueva ${ }^{2}$}

'Escuela de Medicina. Universidad César Vallejo, Trujillo, PERÚ.

2Facultad de Farmacia y Bioquímica. Universidad Nacional de Trujillo, Trujillo, PERÚ.

${ }^{3}$ Escuela de Posgrado. Universidad Nacional de Trujillo, Trujillo, PERÚ.

\section{Correspondence}

\section{Ms. Paúl Alan Arkin Alvarado García}

Escuela de Medicina. Universidad César Vallejo, Trujillo, Av. Larco 1770, Trujillo 13001, PERÚ

Phone no: 0051-998435700;

E-mail: palvaradog@ucvvirtual.edu.pe

History

- Submission Date: 25-08-2021;

- Review completed: 16-09-2021;

- Accepted Date: 22-09-2021.

DOI : 10.5530/pj.2021.13.174

Article Available online

http://www.phcogj.com/v13/i6

Copyright

(C) 2021 Phcogj.Com. This is an openaccess article distributed under the terms of the Creative Commons Attribution 4.0 International license.

\begin{abstract}
Introduction: Essential oils from natural plants are widely use around the world to relief mental conditions. The aim of this investigation was to determine the anxiolytic-like effect of essential oils extracted from Lippia alba and Lippia citriodora. Methods: The oil was extracted by hydro-distillation for 3 hours using a modified Clevenger-type apparatus and then chemical composition was investigated by gas chromatography analysis (GC) and gas chromatography-mass spectrometry (GC-MS). Moreover, a randomized experimental trial was conducted, where 95 participants were divided into 3 groups, comprising a waiting list control group and two experimental groups treated with essential oils by inhalation. The anxiety index was evaluated by State-Trait Anxiety Inventory (STAI). Measures were taken two times: pretest and posttest. Results: chemical analysis showed that carvone was the main component (64.5\%) for Lippia alba essential oil and geranial (39.8\%) for Lippia citriodora. State and Trait anxiety scores showed a decrease in posttest study phase in comparison with pretest in all experimental groups $(p<0.05)$. Cohen's $D$ and Hedges' $G$ scores show a large size effect in state anxiety for experimental group treated with Lippia alba while moderate changes were found for the rest of variables in all experimental groups. Conclusion: the essential oils extracted from Lippia alba and Lippia citriodora may be useful as a mean to counteract anxiety, specifically state anxiety showing short-terms benefits.

Key words: Essential oils, Anxiety, Lippia alba, Lippia citriodora.
\end{abstract}

\section{INTRODUCTION}

COVID-19 pandemic has caused an unprecedented situation around the world, and one of the most significant consequence is the growing increase of mental health problems ${ }^{1}$, even the term coronaphobia was coined to describe the fear and anxiety caused by pandemic ${ }^{2}$, associated to high levels of depression, hopelessness, suicidal ideation, and functional impairment ${ }^{3}$.

Indeed, anxiety is one of the most prevalent psychological problems during the pandemic ${ }^{4}$. According to a research, the prescriptions of antianxiety and sleep aid medication increased for $35.7 \%$ and $41.2 \%$ of the population respectively, because of the pandemic ${ }^{5}$. It is known that benzodiazepines (BDZs) and antidepressants are widely prescribed for anxiety disorders, nevertheless these drugs can produce side effects as lethargy, retrograde amnesia, drowsiness, dizziness, and vertigo $^{6}$, as well to cause physical dependence and tolerance ${ }^{7}$. Besides, the abrupt cessation of BZDs can cause life-threatening seizures, delirium, and death ${ }^{8}$.

Besides, there is a growing acceptation for Complementary and Alternative Medicine (CAM) treatments, since are perceived as natural, lowrisk, economical, with fewer side effects and as effective as conventional drugs ${ }^{9}$. In this context, aromatherapy employs essential oils (EOs), secondary metabolites mainly extracted from leaves, flowers, rhizomes, seeds, barks, and resins of aromatic plants ${ }^{10}$.

EOs are isolated via steam distillation, hydrodistillation, solvent extraction, enfleurage, mechanical pressing, carbon dioxide $\left(\mathrm{CO}_{2}\right)$ and supercritical $\mathrm{CO}_{2}$ extraction, among others ${ }^{11}$. In aromatherapy EOs are applicated trough inhalation, massage, compress, and baths; in addition to being used as therapeutic agents and aesthetics ${ }^{12}$.

Evidence suggests that EOs could alleviate anxiety significantly showing short terms benefits ${ }^{13}$. Besides, a metanalysis found that aromatherapy significantly decreased pain and anxiety in the first stage of labor in nulliparous women ${ }^{14}$. In this order of ideas, a study examined the effects of rosa damascene oil on anxiety and sleep quality in cardiac patients, where this aroma significantly reduced anxiety in the experimental group compared to the control group ${ }^{15}$. In addition, an investigation found that aromatherapy based on EOs is a cost-effective method that can reduce anxiety in hospitalized patients ${ }^{16}$.

Lippia alba and Lippia citriodora are two aromatic shrubs that belong to the Verbenaceae family and have a wide distribution, especially in tropical and subtropical as well as temperate zones of the Americas, Africa, and $\mathrm{Asia}^{17}$. Traditionally, these species are consumed as tea or essential oil in Latin America and Africa due their sedative and tranquilizer properties ${ }^{18}$.

Despite that Lippia species are associated to an anxiolytic effect in traditional medicine and animal models ${ }^{19,20}$, there is lack of evidence about EOs in human models. In this sense, the objective of this study was to determine the anxiolytic-like effect of essential oils extracted from Lippia alba and Lippia citriodora in human volunteers. 


\section{MATERIALS AND METHODS}

\section{Plant material}

The leaves of Lippia alba and Lippia citriodora were collected from Cajamarca, a city in northern highlands of Peru at 2750 masl. The sample collection was conducted in the months of January to February 2021. Voucher specimens were prepared and identified by Segundo Leiva Gonzales, Biol, and deposited at the Herbarium Antenor Orrego (HAO) of Antenor Orrego University.

\section{Essential oils extraction}

The freshly collected leaves were washed with distilled water to remove dust. Then, samples were dried using a forced air circulation stove at a temperature of $40^{\circ} \mathrm{C}$ for $24 \mathrm{~h}$. Next, leaves were milled, and the powdered plant material $(100 \mathrm{~g})$ were placed in a round bottom flask with $1000 \mathrm{ml}$ distilled water, and then connected to a Clevenger-type apparatus. Hydrodistillation was completed for $3 \mathrm{~h}$ after boiling. Then the oil was dried over anhydrous sodium sulphate and stored in a refrigerator in amber glass vials at $4^{\circ} \mathrm{C}$ for further use in experiments ${ }^{21}$. The same procedure was carried out for both species.

\section{Determination of essential oil composition}

Gas chromatography analysis (GC) was performed in a Hewlett Packard 6890 gas chromatograph with a flame ionization detector (FID), using the following conditions: column temperature, $40^{\circ} \mathrm{C}(8$ min) to $180^{\circ} \mathrm{C}$ at $3^{\circ} \mathrm{C} / \mathrm{min}, 180-230^{\circ} \mathrm{C}$ at $20^{\circ} \mathrm{C} / \mathrm{min}, 230^{\circ} \mathrm{C}(20 \mathrm{~min})$; injector temperature $250^{\circ} \mathrm{C}$, detector temperature $250{ }^{\circ} \mathrm{C}$; split ratio 1:50; carrier gas $\mathrm{H} 2(34 \mathrm{KPa})$. Gas chromatography-mass spectrometry (GC-MS) was carried out using a Hewlett-Packard 6890 series gas chromatograph coupled with a mass selective detector Hewlett Packard MSD 5972. The system conditions were the following: fused silica capillary column HP-Innowax ( $30 \mathrm{~m} \times 0.25 \mathrm{~mm}$ i.d., $0.25 \mu \mathrm{m}$ film thickness), column temperature, $40^{\circ} \mathrm{C}(8 \mathrm{~min})$ to $180^{\circ} \mathrm{C}$ at $3^{\circ} \mathrm{C} / \mathrm{min}$, $180-230^{\circ} \mathrm{C}$ at $20^{\circ} \mathrm{C} / \mathrm{min}, 230^{\circ} \mathrm{C}(20 \mathrm{~min})$; interface $280^{\circ} \mathrm{C}$; split ratio 1:100; carrier gas $\mathrm{He}(56 \mathrm{KPa})$; EI mode $70 \mathrm{eV}$. Finally, the identification of essential oil constituents was accomplished by visual interpretation, comparing their retention indices and mass spectra with literature data and with those in the NIST 2011 mass spectra library as well as Wiley library ${ }^{22}$.

\section{Study design and sample}

An experimental study with measures at pretest-posttest was conducted, using two experimental groups and a waiting-list control group. 95 participants were divided into three groups of 32 participants for each experimental group, the first one treated with aromatherapy based on L. alba essential oil (EG1) y the second group treated with L. citriodora essential oil (EG2); and finally, a wait-list (WL) control group with 31 participants.

\section{Study procedure}

A free aromatherapy course was offered through social media to recruit participants. The course was conducted entirely online, due to government restrictions due to the global pandemic. 104 people were enrolled and 95 took part in this investigation between April and May 2021. Inclusion criteria included participants men and female between the ages of 18-55 and they were required to have a State-Trait Anxiety Inventory score of greater than 20 in both scales; meanwhile exclusion criteria were participants with previous practice of alternative therapies such as meditation, tai chi or yoga, psychiatric or psychological treatment, and pregnancy. Participants for each group were randomized by a person not involved in the study by utilization of a random number table. After groups were formed, instruments were administered (pretest). Besides, each participant received weekly an aromatherapy kit with everything they needed for applications, including an instruction manual. Each kit was sent each week to each participant until the investigation was completed. In addition, weekly online meetings were held to monitor the applications and provide feedback. The EOs applications were according to the methodology of Reza, Bazeli, Basiri and Aalami ${ }^{23}$, where the participants were asked to pour two drops of EOs on a cotton ball using a dropper. Next, the cotton ball was held under the participant's nose while closed his or her eyes and took 10 deep breaths. Then, the cotton was pinned to the collar of the participant for 30 minutes. After that, the participant unpinned and disposed the cotton ball. WL control group did not receive any intervention until applications in EG1 and EG2 ended. The applications were every day for 4 weeks. At the end of interventions, an anxiety self-report instrument was administered (posttest). (Fig. 1). When the offered course finished, all participants were informed about the investigation program goals and signed a consent form in which confidentiality and anonymity were guaranteed. The study protocol was approved by Institutional Review Board (IRB) of Universidad Nacional de Trujillo. Besides, this investigation was performed in accordance with the Declaration of Helsinki.

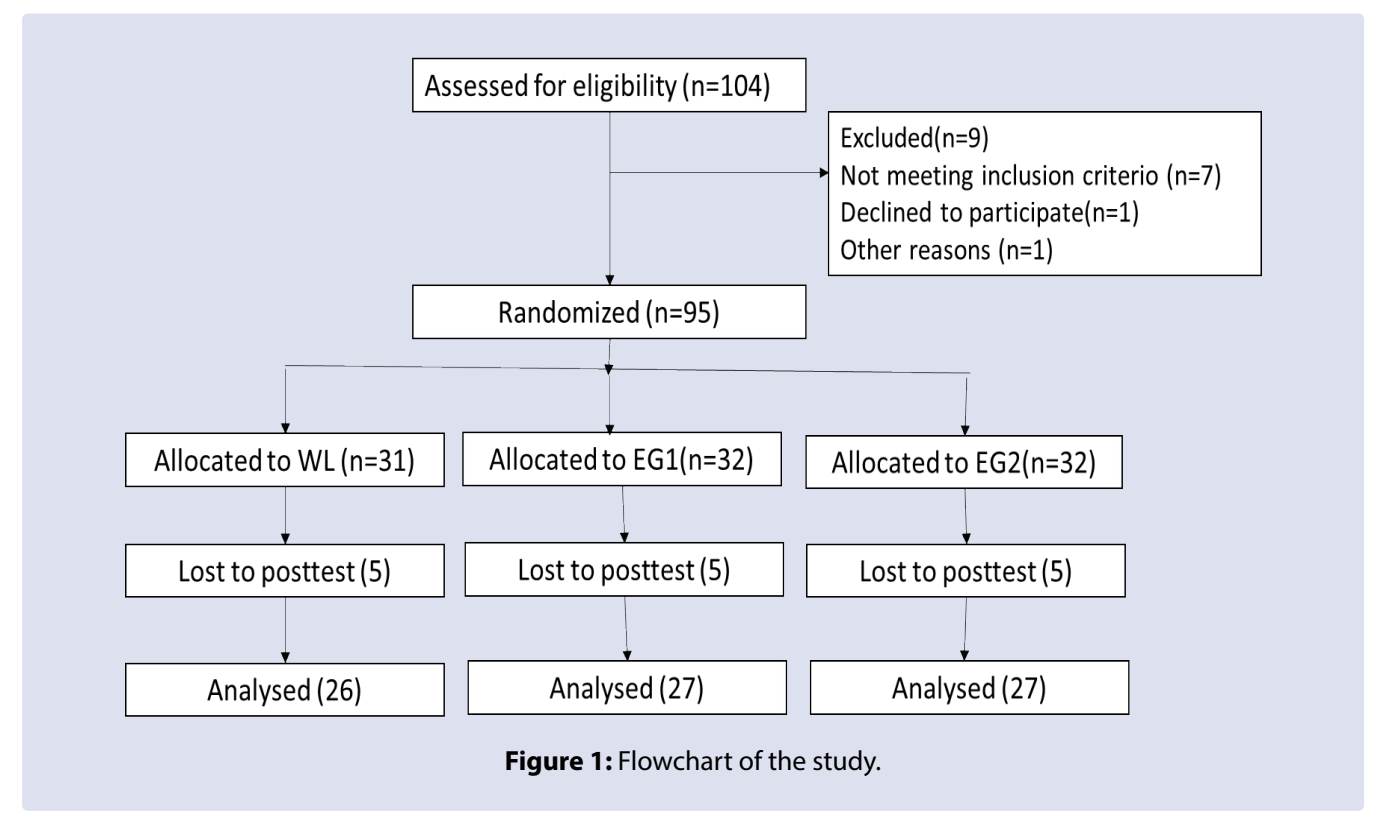




\section{Instruments}

Anxiety was evaluated using the State-Trait Anxiety Inventory "STAI", which consists of two self-report scales measuring two distinct types of anxiety: state (actual levels of intensity and anxiety states) and trait (selects individuals who vary in their tendency to react to psychological stress with varying degrees of intensity). Both scales consist of 20 statements and respondents rate the intensity of their feelings about each at that moment from 1 (not at all) to 4 (very much so). The part that regards trait describes how the subjects generally feel, while the part that regards state describes how they feel at a given moment ${ }^{12,24}$. Inventory was validated for local population in a previous study ${ }^{25}$.

\section{Data Analysis}

Data were presented as mean \pm standard deviation (SD). As data did not conform to the normal distribution, Kruskal-Wallis test was used to determine significant differences between groups, while Wilcoxon test was used to determine significant differences between the study phases. Cohen's D, Hedges' G and Percentage Change were calculated between pretest and posttest scores. All statistical analysis was performed using SPSS v.25.0 (IBM Corp., Armonk, NY, USA).

\section{RESULTS}

Table 1 shows the results from samples analyzed by GC/MS, where 30 components were identified in the essential oil of $L$. alba, representing $98.1 \%$ (area percent) of total oil content, among which the major constituents were carvone $(64.5 \%)$, limonene $(6.3 \%)$, germacrene D (5.8\%), linalool (4.8\%), (E)-Nerolidol (2.6\%), sabinene (2.4\%), a-muurolene(2.3\%), piperitenone (1.9\%) and neral (1.2\%). In the case of the essential oil of $L$. citriodora, 33 components were identified, representing $97.6 \%$ (area percent) of total oil content. among which geranial $(39.8 \%)$, neral $(29.1 \%)$, limonene $(9.6 \%)$, germacrene D (3.6\%), $\beta$-E-ocimene (2.3\%), linalool (1.9\%), $\beta$-caryophyllene $(1.8 \%)$ and sabinene $(1.7 \%)$ were the main constituents.

Table 2 presents socio-demographic and clinical data of analyzed participants where $36(45 \%)$ were male and $44(55 \%)$ were female. WL was formed by $12(46 \%)$ male and 12(54\%) female, while EG1 and EG2 were formed by $12(44 \%)$ male and 15(56\%) female respectively. Most participants were between $25-35$ years old $(n=38 ; 48 \%)$, followed by the participants between $36-55$ years old $(n=32 ; 40 \%)$; and the rest between $18-24$ years old $(\mathrm{n}=10 ; 12 \%)$. In relation to level of education, 42 people (53\%) were graduated, $21(26 \%)$ were postgraduate and 17 (21\%) were undergraduate. In relation to their marital status, 41(51\%) were unmarried, 28 (35\%) were married, 6 (8\%) were divorced and 5 (6\%) participants were widowed.

Table 3 shows the mean score and SDs for anxiety based on STAI, where all groups does not present differences in pretest scores ( $p>0.05$ for state and trait anxiety); somehow, differences are shown in posttest scores ( $\mathrm{p}<0.05$ for state anxiety and $\mathrm{p}<0.05$ for trait anxiety). Besides, anxiety scores show a decrease in posttest study phase as EG1 $(\mathrm{p}<0.005$ for state anxiety and $\mathrm{p}<0.05$ for trait anxiety). These results show a change in STAI scores after the intervention. Meanwhile WL show a slight increase in posttest scores in comparison with pretest scores, but it does not show statistically significant differences $(\mathrm{p}>0.05)$.

Besides, Table 4 shows the scores obtained by the Cohen's D test, Hedges' $G$ and the percentage of change found; where values between 0.5 and 0.8 show moderate changes, as is the case of trait anxiety in EG1 $(\mathrm{d}=0.66 ; \mathrm{g}=0.66)$ and state $(\mathrm{d}=0.78 ; \mathrm{g}=0.78)$ and trait $(\mathrm{d}=0.49$; $\mathrm{g}=0.48)$ anxiety in EG2, while values higher than 0.80 show a large' effect size as evidenced for state anxiety in EG1 $(\mathrm{d}=0.93 ; \mathrm{g}=0.93)$. Likewise, the percentages of change showed that state and trait anxiety in EG1 obtained a percentage of change of $-14.78 \%$, and $-13.18 \%$ respectively, in addition, state and trait anxiety in EG2 obtained a percentage of change of $-11.67 \%$, and $-10.51 \%$ respectively.
Table 1: Main chemical constituents (\%) of the essential oils of Lippia alba and Lippia citriodora.

\begin{tabular}{|c|c|c|c|}
\hline Composition & RI & L. alba & L. citriodora \\
\hline 2-hexenal & 848 & - & $\mathrm{t}$ \\
\hline a-Thujene & 921 & 0.3 & 0.1 \\
\hline a-Pinene & 928 & 0.2 & 1.1 \\
\hline$\beta$-citronellene & 939 & - & $\mathrm{t}$ \\
\hline Sabinene & 960 & 2.4 & 1.7 \\
\hline 1-octen-3-ol & 965 & 0.5 & - \\
\hline$\beta$-Pinene & 984 & 0.5 & 1.0 \\
\hline Myrcene & 989 & 0.4 & 0.2 \\
\hline 3-octanol & 996 & - & 0.1 \\
\hline p-cymene & 1021 & - & $\mathrm{t}$ \\
\hline Limonene & 1026 & 6.3 & 9.6 \\
\hline$\beta$-E-ocimene & 1044 & 0.2 & 2.3 \\
\hline Cis-sabinene hydrate & 1060 & - & 0.3 \\
\hline Linalool & 1094 & 4.8 & 1.9 \\
\hline a-thujone & 1110 & - & 0.5 \\
\hline Trans-limonene oxide & 1130 & $\mathrm{t}$ & 0.8 \\
\hline Terpinen-4-ol & 1170 & - & $\mathrm{t}$ \\
\hline Trans-dihydrocarvone & 1178 & 0.1 & - \\
\hline Carvone & 1224 & 64.5 & - \\
\hline Neral & 1240 & 1.2 & 29.1 \\
\hline Geranial & 1270 & 0.8 & 39.8 \\
\hline Piperitenone & 1310 & 1.9 & - \\
\hline$\delta$-elemene & 1336 & - & 0.4 \\
\hline Eugenol & 1356 & $\mathrm{t}$ & $\mathrm{t}$ \\
\hline a-copaene & 1373 & 0.5 & 0.2 \\
\hline$\beta$-bourbonene & 1385 & 0.4 & 1.1 \\
\hline$\beta$-cubebene & 1392 & 0.3 & $\mathrm{t}$ \\
\hline$\beta$-caryophyllene & 1420 & 0.5 & 1.8 \\
\hline Aromadendrene & 1455 & 0.4 & 0.5 \\
\hline Germacrene D & 1476 & 5.8 & 3.6 \\
\hline a-muurolene & 1495 & 2.3 & 0.4 \\
\hline$\gamma$-cadinene & 1508 & 0.1 & 0.1 \\
\hline$\delta$-cadinene & 1520 & 0.2 & 0.3 \\
\hline (E)-Nerolidol & 1575 & 2.6 & 0.1 \\
\hline a-muurolol & 1631 & 0.1 & 0.2 \\
\hline a-cadinol & 1654 & 0.1 & 0.4 \\
\hline (E)-Phytol & 2080 & 0.8 & $\mathrm{t}$ \\
\hline Nd & 2232 & 0.1 & - \\
\hline Total identified (\%) & & 98.1 & 97.6 \\
\hline
\end{tabular}

$\mathrm{RI}$, Retention index; $\mathrm{t}=$ traces $(<0.1 \%)$; $\mathrm{Nd}$, Not determined

\section{DISCUSSION}

EOs are metabolites of plants that are typically oily liquids at ambient temperatures. In this case, chemical composition showed that $L$. alba essential oil can be classified as carvone chemotype due to this component is the main according to outcomes. This agrees with data from other investigations where it is also reported this chemotype for Peru $^{26,27}$. However, L. citriodora essential oil showed that geranial, neral and limonene were the compounds where the major quantitative differences were observed. Although it is true that there are no studies on the chemical composition of the essential oil of this species in Peru, this coincides with other studies where they also show these two components as the main ones in the composition of this essential oil ${ }^{28,29}$.

Regarding socio-demographic data of participants, the majority were adults with graduate and postgraduate level of education. This is in concordance with some studies which affirm that most educated population is more likely to be interested in complementary and 
Table 2: Socio-demographic and clinical data of participants.

\begin{tabular}{|c|c|c|c|c|}
\hline Socio-demographic data & WL & EG1 & EG2 & Total \\
\hline \multicolumn{5}{|l|}{ Gender } \\
\hline Male & $12(46 \%)$ & $12(44 \%)$ & $12(44 \%)$ & $36(45 \%)$ \\
\hline \multicolumn{5}{|l|}{$\operatorname{Age}(y r)$} \\
\hline $18-24$ & $4(15 \%)$ & $3(11 \%)$ & $3(11 \%)$ & $10(12 \%)$ \\
\hline \multicolumn{5}{|l|}{ Level of education } \\
\hline Undergraduate & $5(19 \%)$ & $6(22 \%)$ & $6(22 \%)$ & $17(21 \%)$ \\
\hline Graduate & $4(54 \%)$ & $14(52 \%)$ & $14(52 \%)$ & $42(53 \%)$ \\
\hline Postgraduate & $7(27 \%)$ & $7(26 \%)$ & $7(26 \%)$ & $21(26 \%)$ \\
\hline Divorced & $2(8 \%)$ & $2(7 \%)$ & $2(7 \%)$ & $6(8 \%)$ \\
\hline Widowed & $1(4 \%)$ & $2(7 \%)$ & $2(7 \%)$ & $5(6 \%)$ \\
\hline
\end{tabular}

Table 3: Group differences of anxiety variable according to State-Trait Anxiety Inventory.

\begin{tabular}{|c|c|c|c|c|c|}
\hline \multirow{2}{*}{ Groups } & \multicolumn{2}{|c|}{ Pretest } & \multicolumn{2}{|c|}{ Posttest } & \multirow{2}{*}{$p$-Value ${ }^{b}$} \\
\hline & Mean & SD & Mean & SD & \\
\hline \multicolumn{6}{|l|}{ WL } \\
\hline Trait Anxiety & 32.13 & \pm 5.16 & 32.23 & \pm 6.49 & 0.899 \\
\hline \multicolumn{6}{|l|}{ EG 1} \\
\hline \multicolumn{6}{|l|}{ EG 2} \\
\hline \multirow[t]{2}{*}{ State Anxiety } & 39.84 & \pm 5.90 & 35.19 & \pm 5.15 & $0.001^{*}$ \\
\hline & 0.934 & & $0.003^{*}$ & & \\
\hline Trait Anxiety & 32.44 & \pm 5.02 & 29.03 & \pm 6.57 & $0.024^{*}$ \\
\hline
\end{tabular}

${ }^{*} \mathrm{p}<0.05$

${ }^{a} \mathrm{p}$-value is calculated by Kruskal-Wallis test between groups

${ }^{b} \mathrm{p}$-value is calculated by Wilcoxon test between study phases

Table 4: Cohen's D, Hedges' G and Percentage Change in intervention groups.

\begin{tabular}{lccc} 
Group & Cohen's D Posttest & Hedges' G Posttest & $\begin{array}{c}\text { \% Of change } \\
\text { Pretest-Posttest }\end{array}$ \\
\hline EG1 & & & -14.78 \\
State Anxiety & 0.93 & 0.93 & -13.18 \\
Trait Anxiety & 0.66 & & -11.67 \\
EG2 & & 0.78 & -10.51 \\
State Anxiety & 0.78 & 0.48 & \\
Trait Anxiety & 0.49 & &
\end{tabular}

alternative medicine therapies like aromatherapy ${ }^{30}$. Nevertheless, this point constitutes one of the limitations because only few participants belonged to least educated population and our study does not show how these therapies can work in a different population, besides, the participant number is insufficient hence results cannot be generalized.

Literature describes that EOs can regulate brain health and functions associated with mood, anxiety and depression ${ }^{31}$. Indeed, evidence in anxiety animal models and some clinical trials show that EOs used in aromatherapy can alleviate anxiety symptoms ${ }^{10}$. This data agrees with our findings where participants in EG1 and EG2 show a decrease in anxiety scores after intervention. Although it is true that anxiety levels are still high according to STAI, the decrease in anxiety scores generates a certain effect size denoting the intervention effectivity. In this sense, state anxiety scores showed a large size effect in EG1, however it was found medium size effect in outcomes belonging to the rest of categories in both experimental groups. This is in accordance with other studies which investigated the effectiveness of EOs in reducing state anxiety ${ }^{32}$. A meta-analysis indicated that aromatherapy could mitigate especially temporary anxiety ${ }^{13}$. It is also remarkable to affirm that state anxiety is related to temporary situations that changes every moment and when disappear, the individual no longer experience anxiety, but trait anxiety is related to permanent personality features of people ${ }^{33}$.

Moreover, significant differences between experimental groups may be due to the fact of difference constitution of the two essential oils tested. In view of this, $L$. alba essential oil shows the major quantitative differences in components with anxiolytic effect in comparison with $L$. 
citriodora. Indeed, carvone is considered as a depressor of the central nervous system, interacting with $\mathrm{GABA}_{\mathrm{A}}$ receptors in the brain after crossing the blood-brain barrier ${ }^{34}$. The mechanism is similar to BDZs that exert a positive allosteric modulatory effect increasing inhibitory GABAergic neurotransmission ${ }^{35}$. Furthermore, the highest amount of linalool was found in L. alba compared to L. citriodora. The evidence about anxiolytic effect of linalool inhalation is widely reported, although its anxiolytic mechanism of action is not clearly, studies suggest that anxiolytic effects are triggered by olfactory input evoked by linalool odor exposure that activate anxiolytic circuits involving GABAergic transmission via BDZ-responsive $\mathrm{GABA}_{\mathrm{A}} \mathrm{R}^{36}$.

Limonene is another component present in both EOs, in this case, a study demonstrate that this component can inhibit anxiety-related behavior through A2A receptor-mediated regulation of DAergic and GABAergic neuronal activity ${ }^{37}$. Besides it is possible that terpenes such as geranial and neral present in L. citriodora, also exert anxiolytic action $^{38}$. However, not only EOs components by themselves may present anxiolytic effects, but there is also evidence that properties of EOs cannot be attributed to a single component because these could be the result of the synergistic effects of its constituents ${ }^{39}$.

\section{CONCLUSION}

According to our investigation, the essential oils extracted from Lippia alba and Lippia citriodora may be useful as a mean to counteract anxiety, specifically state anxiety showing short-terms benefits.

\section{CONFLICTS OF INTEREST}

The authors declare no conflicts of interest.

\section{REFERENCES}

1. Chaturvedi S K. Covid-19, Coronavirus and Mental health Rehabilitation at Times of Crisis. J Psychosoc Rehabil Ment Health. 2020; 7:1-2.

2. Asmundson GJG, Taylor S. Coronaphobia: Fear and the 2019-nCoV outbreak. J Anxiety Disord. 2020; 70: 102196.

3. Lee SA, Jobe MC, Mathis AA. Mental health characteristics associated with dysfunctional coronavirus anxiety. Psychol Med. 2020;1-2. DOI:10.1017/S003329172000121X

4. Salari N, Hosseinian-Far A, Jalali R, Vaisi-Raygani A, Rasoulpoor S, Mohammadi M, Rasoulporr S, Khaledi-Paveh B. Prevalence of stress, anxiety, depression among the general population during the COVID-19 pandemic: a systematic review and meta-analysis. Glob Health. 2020;16:1-11.

5. Grigsby TJ, Howard, JT, Deason RG, Haskard-Zolnierek KB, Howard K. Correlates of COVID-19 pandemic-related increases in sleep aid and anti-anxiety medication use. J Subst Abuse. 2021. DOI: 10.1080/14659891.2021.1892221.

6. Nash JR, Nutt DJ. Pharmacotherapy of anxiety. Handb Exp Pharmacol.2005; 169:469-501.

7. Fluyau D, Revadigar N, Manobianco BE. Challenges of the pharmacological management of benzodiazepine withdrawal, dependence, and discontinuation. Ther Adv Psychopharmacol. 2018;8: 147-168.

8. Brett J, Murnion B. Management of benzodiazepine misuse and dependence. Aust Prescr 2015; 38: 152-155.

9. Sajatovic M, Levin J, Fuentes-Casiano E, Cassidy KA, Tatsuoka $\mathrm{C}$, Jenkins $\mathrm{JH}$. Illness experience and reasons for nonadherence among individuals with bipolar disorder who are poorly adherent with medication. Compr Psychiatry. 2011;52:280-287.

10. Zhang N, Yao L. Anxiolytic Effect of Essential Oils and Their Constituents: A Review. J Agric Food Chem. 2019; 67:1379013808.
11. Hanif MA, Nisar S, Khan GS, Mushtaq Z, Zubair M. Essential Oils. In: Malik S. (eds) Essential Oil Research. Switzerland: Springer; 2019. pp. 3-17.

12. Kutlu AK, Yilmaz E, Çeçen D. Effects of aroma inhalation on examination anxiety. Teach Learn Nurs. 2008; 3:125-130.

13. Gong M, Dong H, Tang Y, Huang W, Lu F. Effects of aromatherapy on anxiety: A meta-analysis of randomized controlled trials. J Affect Disord. 2020; 274:1028-1040.

14. Liao CC, Lan SH, Yen YY, Hsieh YP, Lan SJ. Aromatherapy intervention on anxiety and pain during first stage labour in nulliparous women: a systematic review and meta-analysis. J Obstet Gynaecol. 2021; 41:21-31.

15. Jodaki K, Abdi K, Mousavi MS, Mokhtari R, Asayesh H, Vandali V, Golitaleb M. Effect of rosa damascene aromatherapy on anxiety and sleep quality in cardiac patients: A randomized controlled trial. Complement. Ther Clin Pract. 2021;42: 101299.

16. Nematollahi MR, Bazeli J, Moghaddam MB, Aalami H. Effect of aromatherapy on anxiety in patients with acute coronary syndrome hospitalized in cardiac care unit. Bali Med J.2017; 6:331-336.

17. Hennebelle T, Sahpaz S, Joseph H, Bailleul F. Ethnopharmacology of Lippia alba. J Ethnopharmacol 2008; 116:211-22.

18. González-Trujano ME, Hernández-Sánchez LY, Muñoz V, DorazcoGonzález A, Guevara P, Aguirre-Hernández E. Pharmacological evaluation of the anxiolyticlike effects of Lippia graveolens and bioactive compounds. Pharm Biol. 2017; 55:1569-1576.

19. Bandeira G, Sander M, Dos Santos JG, Garrido C, Heinzmann BM, Otomar B et al. Lippia alba and Aloysia triphylla essential oils are anxiolytic without inducing aversiveness in fish. Aquaculture. 2018; 482:49-56

20. Bonyani A, Sajjadi SE, Rabbani M. Anxiolytic effects of Lippia citriodora in a mouce model of anxiety. Res Pharm Sci. 2018; 13 205-212.

21. Ciccio JF, Ocampo RA. Variación anual de la composición química de aceite esencial de Lippia alba (Verbenaceae) cultivada en Costa Rica. Lankesteriana 2006; 6: 149-54.

22. Tomazoni EZ, Pansera MR, Pauletti GF, Moura S, Ribeiro RTS Shwambach J. In vitro antifungal activity of four chemotypes of Lippia alba (Verbenaceae) essential oils against Alternaria solani (Pleosporeaceae) isolates. An Acad Bras Ciênc 2016; 88: 999-1010.

23. Reza M, Bazeli J, Basiri M, Aalami H. Effect of aromatherapy on anxiety in patients with acute coronary syndrome hospitalized in cardiac care unit. Bali Med J. 2017; 6:331-336.

24. $\mathrm{Hu} \mathrm{PH}$, Peng YC, Lin YT, Chang CS, Ou MC. Aromatherapy for reducing colonoscopy related procedural anxiety and physiological parameters: a randomized controlled study. Hepatogastroenterology 2010; 57:1082-86

25. Soto-Vásquez MR, Alvarado-García PAA. Aromaterapia a base de aceite esencial de "satureja brevicalyx" "inka muña" y meditación mindfulness en el tratamiento de la ansiedad. Med Nat 2016; 10:47-52.

26. Leclercq PA, Silva H, García J, Hidalgo JE, Cerruti T, Mestanza M et al. Aromatic Plant Oils of the Peruvian Amazon. Part 1. Lippia alba (Mill.) N.E. Br. and Cornutia odorata (Poeppig) Poeppig ex Schauer, Verbenaceae. J Essent Oil Res 1999; 11:753-56.

27. Soto-Vásquez MR, Alvarado-García PAA. Anxiolytic-like effect of Lippia alba essential oil: A randomized, placebo-controlled trial. J Complement Med Res. 2018; 7:101-107.

28. Santos-Gómez PC, Fernandes-Ferreira M, Vicente A. Composition of the Essential Oils from Flowers and Leaves of Vervain [Aloysia triphylla (L'Herit.) Britton] Grown in Portugal. J Essent Oil Res. 2005; 17:73-78.

29. Argyropoulou C, Daferera D, Tarantilis PA, Fasseas C, Polissiou. hemical composition of the essential oil from leaves of Lippia citriodora H.B.K. (Verbenaceae) at two developmental stages. 2007; 35:831-837. 
30. Hawk C, Ndetan H, Evans Jr MW. Potential role of complementary and alternative health care providers in chronic disease prevention and health promotion: an analysis of National Health Interview Survey data. Prev Med. 2012; 54:18-22.

31. Aponso M, Patti A, Bennett LE. Dose-related effects of inhaled essential oils on behavioural measures of anxiety and depression and biomarkers of oxidative stress. J Ethnopharmacol. 2020; 250:112469.

32. Barati F, Nasiri A, Akbari N, Sharifzadeh G. The Effect of Aromatherapy on Anxiety in Patients. Nephrourol Mon 2016; 8: e38347.

33. Ursache A, Raver CC. Trait and State Anxiety: Relations to Executive Functioning in an at Risk Sample. Cogn. Emot. 2014; 28: 845-855.

34. Hatano VY, Torricelli AS, Giassi ACC, Coslope LA, Viana MB. Anxiolytic effects of repeated treatment with an essential oil from Lippia alba and (R)-(-)-carvone in the elevated T-maze. Braz J Med Biol Res. 2012; 45: 238-43.
35. Rudolph, U.; Knoflach, F. Beyond classical benzodiazepines:Novel therapeutic potential of GABAA receptor subtypes. Nat Rev Drug Discovery. 2011;10: 685-697.

36. Harada H, Kashiwadani H, Kanmura $Y$, Kuwaki T. Linalool Odorinduced anxiolytic effects in mice. Front Behav Neurosci. 2018; 12: 241.

37. Song $Y$, Seo S, Lamichhane S, Seo J, Hong JT, Cha HJ, Yun J. Limonene has anti-anxiety activity via adenosine $A 2 A$ receptormediated regulation of dopaminergic and GABAergic neuronal function in the striatum. Phytomedicine. 2021; 83:153474.

38. Bonyani A, Sajjadi SE, Rabbani M. Anxiolytic effects of Lippia citriodora in a mouce model of anxiety. Res Pharm Sci. 2018; 13:2052012

39. Okano S, Honda Y, Kodama T, Kimura M. The Effects of Frankincense Essential Oil on Stress in Rats. J Oleo Sci. 2019: 68:1003-1009.

\section{GRAPHICAL ABSTRACT}

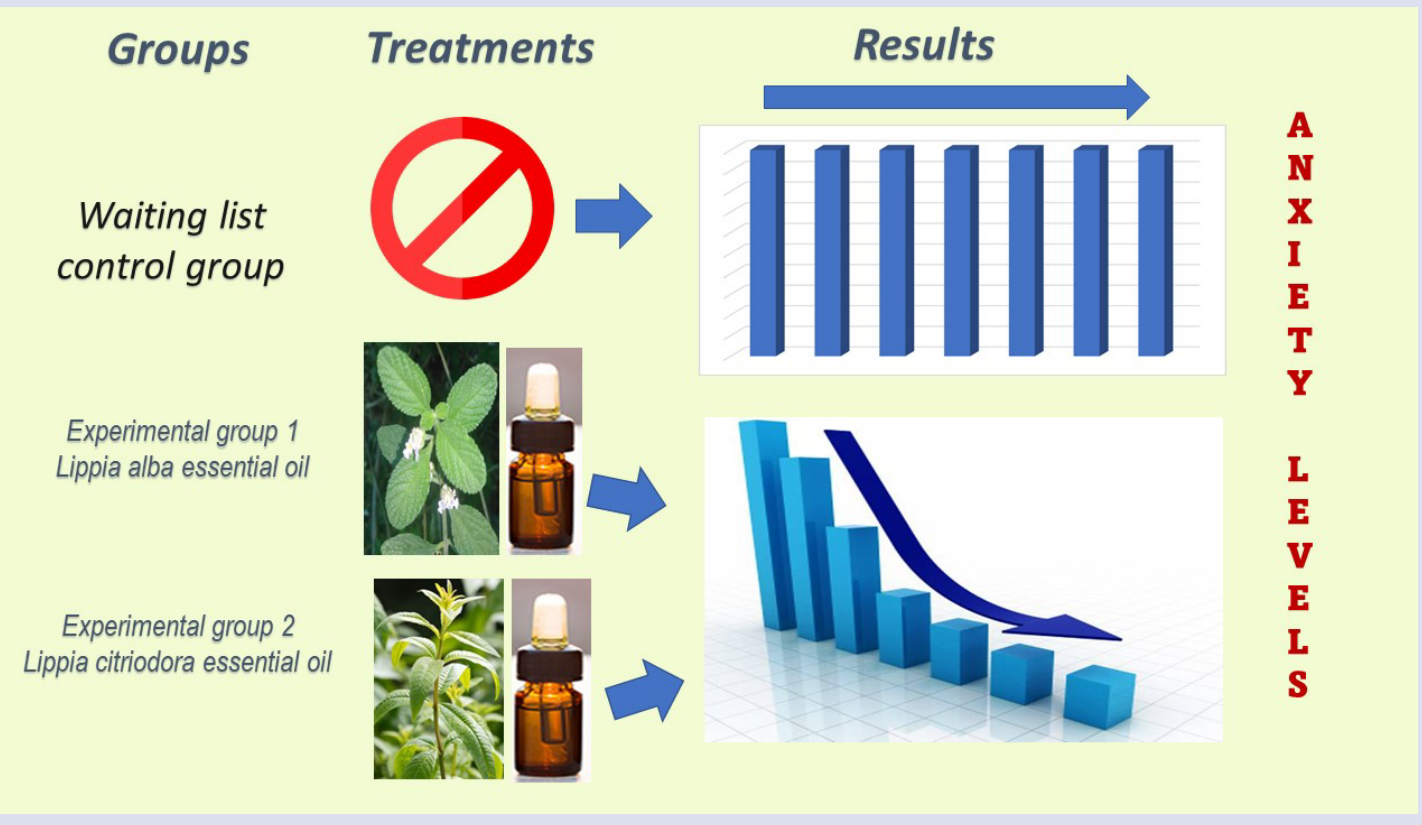




\section{ABOUT AUTHORS}
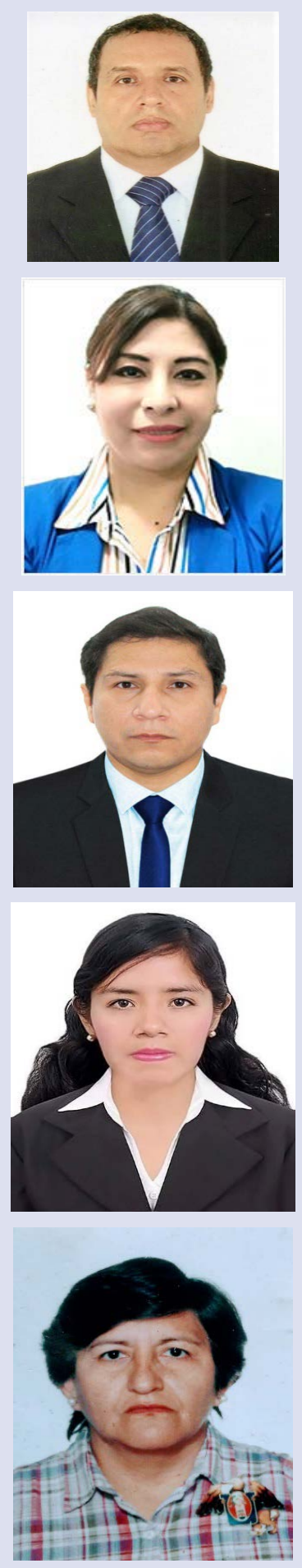

\section{Ms. Paul Alan Arkin Alvarado García}

Master of Education. Professor at the Medicine School of Universidad César Vallejo. Develops research in Mental health problems, Complementary and Alternative Medicine, and natural products applicated to stress, anxiety, and depression.

\section{Dra. Marilú Roxana Soto-Vásquez}

Doctor in Pharmacy and Biochemistry, professor of the chairs of pharmacognosy, phytochemistry, pharmaceutical botany of Faculty of Pharmacy and Biochemistry of Universidad Nacional de Trujillo. Develops Research in Natural Products with antiprotozoal, antitumor, antimicrobial activities, and Complementary and Alternative Medicine.

\section{Luis Enrique Rosales-Cerquin}

Gynecologist and obstetrics specialist. Professor at the Medicine School of Universidad César Vallejo. Develops research in reproductive health, natural products, and Integrative medicine.

\section{Pharm. Bertha Mirella Alfaro-Ttito}

Chemical pharmaceutical, student at Postgraduate School of National University of Trujillo, section Natural Products. Research Assistant in Natural Products.

\section{Dra. Elda Maritza Rodrigo-Villanueva}

Doctor in Pharmacy and Biochemistry, professor of the chairs of Investigation methodology. Develops Research in Natural Products.

Cite this article: Alvarado-Garcia PAA, Soto-Vásquez, MR, Rosales-Cerquin LE, Alfaro-Ttito BM, Rodrigo-Villanueva EM. Anxiolyticlike Effect of Essential Oils Extracted from Lippia alba and Lippia citriodora. Pharmacogn J. 2021;13(6): 1377-1383. 